New areas in AIDS research

Stockholm

A VARIETY of pleas marked the closing stages of the IVth International Conference on AIDS. Loudest among them were calls for more basic virology, more sex research. more attention to other sexually transmitted diseases and an intensified search for an animal model (see page 699).

"There is a future in turning back to the past", was how David Baltimore, director of the Whitehead Institute for Medical Research, couched his plea. We have learnt a great deal about the sequence variations of human immunodeficiency virus (HIV) and its genes, he said, because that was what was most easy to explore when the virus was discovered. But relatively little is known of the basic life cycle of the virus.

It is necessary to go back to a basic virological study of HIV to try and find chinks in its armour, Baltimore argued. "We are too concerned with drugs and vaccines", given that it is now clear they are not easy to come by. More needs to be learnt about regulation of the life cycle of HIV.

King Holmes, of Harborview Medical Center in Seattle, pleaded for more to be spent on the study of sexually transmitted diseases that cause genital ulcers and for the control of chlamydial infections because both are strongly implicated as risk factors for HIV transmission. It is disastrous, he said, that the control of chlamydial infections has been stalled for the past four years because funds have been diverted to AIDS research. There is little cause for complacency in the slow growth of AIDS associated with heterosexual transmission of HIV in view of the alarming spread of sexually transmitted diseases in some population groups.

While calling for much more research on human sexual behaviour, in part to provide the data necessary to model the spread of HIV, John Gagnon of Princeton University warned that many poorly designed and inadequately performed sex surveys lead to "blind alleys, out of which people must publish their way". He lamented the fact that it has taken AIDS to stimulate the need for surveys; that they are necessary is evident by the continued reliance on the Kinsey Report.

A number of adequate studies of sexual habits in the United States, Europe, Africa and South America are now in the planning stage, Gagnon said. He welcomed the controversial involvement of homosexuals and prostitutes in such studies, for they may best help to define the questions that should be asked.

Peter Newmark

\title{
Plans for altered lymphocyte release in humans
}

Washington

Two researchers at the US National Institutes of Health (NIH) are seeking permission to perform a controversial experiment requiring the administration of genetically-engineered cells to people. If authorized, it will be the first officiallysanctioned experiment in which human cells altered by recombinant DNA techniques are returned to the body.

The experiment, proposed by Steven A. Rosenberg of the National Cancer Institute $(\mathrm{NCI})$ and $\mathrm{W}$. French Anderson of the National Heart, Lung and Blood Institute, will track lymphocytes which have been activated to fight cancer as part of the tumour-infiltrating lymphocyte (TIL) therapy developed by Rosenberg.

In this technique, so far effective only in patients with skin and renal cancer, lymphocytes which have already proven their

\section{Drastic measures proposed in India}

\section{New Delhi}

Sexual intercourse with foreign nationals will be made a punishable offence under legislation that the Indian Council of Medical Research (ICMR) has asked the Health Ministry to introduce parliament in February 1989. The controversial proposal is one of ICMR's strategies to check the spread of AIDS in India.

According to Dr A.S. Paintal, directorgeneral of ICMR, the proposal was favourably received by the Ministry of Health and other relevant ministries. But the Law Ministry says it violates the constitutional right of privacy. ICMR, which says the constitution must be amended if possible, plans to elicit public opinion through nationwide debates and seminars. A national conference is scheduled for January 1989 and its recommendation will be presented to the parliament the following month.

Paintal, who believes that AIDS is an imported disease, is personally behind this move. He fears that there is a real danger of AIDS flaring up in India through sexual contacts with visiting foreigners. A law banning such contacts is seen as a preventive measure. It will not harass the foreigners, but Indians caught in the act will pay a fine of Rs20.000 and will spend three months in gaol.

One question Paintal has not answered is whether it is practical to enforce the act without an army of inspectors peeping into bedrooms through keyholes. ICMR admits that catching offenders will pose a problem but hopes the mere existence of the law would act as a deterrent. K.S. Jayaraman anticancer ability by invading a tumour are sclectively stimulated to grow by excising the tumour and treating it with interleukin-2 (IL-2). The purified tumourinvading lymphocytes are then returned to the patient with additional IL-2, in the hope that the activated lymphocytes will attack the remaining cancerous tissue.

There is now no way to trace the movements of the reintroduced lymphocytes to prove that the strategy is working, because the half-lives of the radioactive labels which are safe for use in people are too short. Rosenberg and Anderson plan to introduce the gene for neomycin resistance into the activated lymphocytes before they are administered to the patient in order to follow their action in TIL therapy.

By strict definition, the proposed experiment is not gene therapy, because it will not replace a gene whose absence or defect is causing disease. Rather, the experiment can be likened to environmental releases of recombinant organisms where genes which allow the identification of the altered organisms are introduced instead of a functional genes producing a desired product.

The bulk of Anderson's research has been on developing a therapy for infants with severe combined immune deficiency (SCID) who lack a functional gene for the basic enzyme adenosine deaminase (ADA). Anderson and his coworkers are laying the groundwork to allow them to restore the normal operations of SCID patients' immune systems by inserting the ADA gene into cells from their bone marrow using a retroviral vector.

Before the marker experiment outlined by Rosenberg and Anderson can proceed, it must be approved by the human experimentation board at the NCI, the Gene Therapy Working Group of the Recombinant DNA Advisory Committee, and several other bodies. If the experiment is approved and proves successful, the next step would be to engineer the lymphocytes to produce larger quantities of their own IL-2, removing the necessity for follow-up IL-2 injections which cause side-effects.

The only other experiments which have involved treating humans with genetically-engineered cells were performed in 1980 by Martin J. Cline of the University of California at Los Angeles. Cline attempted unsuccessfully to insert haemoglobin genes into patients in Italy and Israel to cure them of beta-thalassaemia. Because Cline conducted the experiments without undergoing the review process to weigh the risks and benefits of the therapy, he is no longer eligible to receive federal funds for his research.

Carol Ezzell 